\title{
Open, transparent management and the media: The managers' perspectives
}

\author{
Lotta Dellve ${ }^{* 1,2}$, Christian Jacobsson ${ }^{3}$, Maria Wramsten Wilmar $^{3}$ \\ ${ }^{1}$ Department of Sociology and Work Science, University of Gothenburg, Gothenburg, Sweden \\ ${ }^{2}$ Academy of Health, Work and Wellfare, University of Borås, Borås, Sweden \\ ${ }^{3}$ Department of Psychology, University of Gothenburg, Gothenburg, Sweden
}

Received: October 24, 2016

DOI: $10.5430 /$ jha.v6n2p1
Accepted: December 29, 2016 Online Published: February 13, 2017

URL: http://dx.doi.org/10.5430/jha.v6n2p1

\begin{abstract}
Objective: Delivery of health care service (HCSs) is a public issue in Sweden. Managers' decisions and strategies are expected to be open to debate, investigation and scrutiny by the media. There is, however, little knowledge about how managers at local level communicate with the media. The aim of this study is to present an empirically grounded conceptual model of how operative health care managers perceive and handle media communication in open, transparent management of public HCSs.

Methods: A grounded theory approach was adopted including in-depth and follow-up interviews with 45 managers, and complemented with open-ended questions that were answered by the majority of municipal top managers of public HCSs in Sweden $(\mathrm{n}=161)$.

Results: Communicating with the media were interacting in spite of unequal logics and conditions regarding openness in communicating. In managers response to media misrepresentation (inaccurate, narrow and skewed reporting) of the often complex and value-laden issues of HCSs they put highlighted dignity, correctness regarding facts, and protection of integrity. Managers' approaches were to mobilize individual and organizational resources in order to support openness and reduce uncertainties, through crafting managerial hardiness and organizational robustness, and over the longer term, by building authentic openness through awareness, control and acceptance of the conditions.

Conclusions: In conclusion, handling the media can be challenging owing to different logics for reporting, but the media plays a vitally important role in the transparency of the management. Dealing with the pressure of media attention can either have negative consequences or contribute to more open and authentic internal and external communication.
\end{abstract}

Key Words: Leadership, Management, Strategies, Media, Approaches, Support, Open government

\section{INTRODUCTION}

The media has an important role in debating health issues and investigating health care services (HCSs), thereby increasing and sustaining democratic processes and the public's influence and ensuring transparency and quality in service provision. Steps to increase the public's influence on and insights into HCSs are being taken, one example being the
European Union (EU) policy of open governance of public organizations. In terms of this, transparency with open processes, priorities and decisions is increasingly important. Despite today's intense reorientation of health care, which implies public debate and the development of policies of open, transparent governance, the scientific knowledge about managerial approaches to handling media communication

\footnotetext{
*Correspondence: Lotta Dellve; Email: lotta.dellve@gu.se; Address: Department of Sociology and Work Science, University of Gothenburg, Gothenburg, Sweden.
} 
in a society that fosters open management practices is poor. The aim of this study is to present an empirically grounded conceptual model of how health care managers perceive and handle media communication in open, transparent management of public HCSs.

Transparency and openness is one of the EU's criteria and there has been a societal trend towards more open management in the public sector (see, e.g., the open data policy outlined in Public Sector Information, Directive 2003/98/EC, and implemented in early 2013). The objective is to contribute to organizational, community and societal development through increased availability, more effective and better service to members of the public, and increased participation in democratic processes involving important public services. ${ }^{[1,2]}$ In Sweden in 2006, the Swedish Association for Local Authorities and Regions introduced the first "open comparisons of indicators of quality in HCSs" (www.skl.se/oppna-jamforelser-av-halso -och-sjukvarden). Another way of involving the public is through web-based contacts with patients, made at county council level. ${ }^{[3,4]}$

At the local level, there have been several approaches to increasing availability and effectiveness of, and better service in, health care. However, ways still need to be found to communicate with the public so as to increase their influence in the HCSs, other than through direct patient meetings. In this respect, the news media have come to play an important role with regard to open communication with the HCSs. The interest in health issues discussed in the media has increased among the Swedish public during the last 10-20 years and health is today among the top ranked topics. ${ }^{[5]}$ The media have, during the same time period, expanded their focus from political aspects and more standardized formulations of HCS issues to increased reporting of everyday conditions in health care practice. ${ }^{[6]}$ Thus, in Sweden, the media often turn to managers at operative level to get more detailed descriptions of the local HCS from within the service.

An important part of leadership is to maintain good public relations outward and care for the public image of the organization. ${ }^{[7]}$ Today in the new public management (NPM) era, it seems increasingly important that "things look good", which implies that management work in our day is guided by logics supporting rhetoric, image and reputation when developing structures that are based on norms (rather than on work in practice) of what a modern organization should look like, and thus on protecting the organization's reputation. ${ }^{[8-10]}$ Here, the news media play a central role as they create and carry ideas about organizations and their leaders, e.g. as celebrated or condemned. ${ }^{[11,12]}$
The focus on managers in the media can be related to NPM ideologies, ${ }^{[13]}$ media logics ${ }^{[14]}$ and dynamics of uncertainty in the managerial role within the organization during critical media attention. ${ }^{[15]}$ Media communication can put hard pressure and special demands on managers. Especially the use of intense negative personification on the managers has been related to stress reactions, such as keeping a narrow perspective and avoidance of confrontations, which may have an impact on open management. ${ }^{[15]}$ Also, lack of support within the organization during media attention can have an impact on managers' experience and can affect reporting. ${ }^{[16]}$ These conditions may have an impact on true open, transparent management in health care. There is little knowledge about how managers cope with hard media pressure and the expectations of open management. The approaches, practices and conditions supporting open management of health care organizations have, to our knowledge, not been previously studied.

\section{METHOD}

\subsection{Design}

Because this is a new research topic we used a grounded theory approach. Grounded theory is an approach that supports the analyses of social processes at different levels, such as the interaction between managers and the media. ${ }^{[17]}$ This method gives the researcher freedom to generate new concepts explaining human behaviours and to develop an empirically grounded theory. Qualitative interviews with managers at all levels of health care were the main source of data. Additionally, a questionnaire with open-ended questions for top managers was used to complement the data collection.

\subsection{Process of sampling, data collection and analysis}

The grounded theory approach allows and encourages datacollection and analyses of data in parallel, analyses of relevant data from multiple sources and, refinement of questions according to saturate the developing empirical model. ${ }^{[17]}$ In interviews, we explored managers' approaches when meeting, communicating with and handling the media. Managers with top, middle or lower-level management positions in hospital organizations or municipal health and social services were interviewed once or twice during 2008-2014 $(n=45)$. We selected managers of health and social care organizations from across Sweden. The sampling was strategic to collect as wide as possible a range of experiences of communication with the media, show variation between municipal and county regional health organizations and obtain geographic coverage (urban versus rural; middle-sized municipality, industrial municipality, city). But, we did not interview managers in cases where there was a suspected crime connected to media attention. Firstly, we focused the interviews to managers 
with negative experience of media attention, in most cases connected to a certain situation (these interviews were conducted by all authors but most MWW). These managers were selected through contact with personnel or via information functions, by studying newspapers and through snowball sampling (where the interviewed managers were asked to name a colleague with experience of media attention). In some cases, the interviewee's senior manager, human resource (HR)/communication contact or colleague within the organization was also interviewed. These interviews provided rich data about the personal negative experience of communicating with media. Secondly, to get a wider understanding of how operative health care managers perceive and handle media communication, we selected managers in public HCSs in positions where experience of media attention reasonably was a part of their work (emergency/ambulance managers, medical responsible managers). These interviews provided rich data about how managers were using their personal and organizational resources to meet media and keep an open communication about the HCS they were in charge of. The in-depth interviews focused around the following questions:

- Have you experience of being spoken of in the media? How did you experience it? (your thoughts, emotions, handlings related to be personally focused, to the situation and to related events)

- Have you been affected by it as a private person and/or as a manager, how?

- How did your immediate surroundings react and handle the situation?

- How was the media situation communicated in the organization? Did the situation have any consequences for relationships, communication and climate at work, how?

Additionally, interviews conducted in the first round were followed up by shorter interviews by phone (1-3 years later) with those that still had a managerial position and accepted to be interviewed $(n=15)$ (these interviews were conducted by LD). The interviews started by the question: If you look back at the situation and the time afterwards: What are the main lessons you have learned from the experiences of media attention - and the organization seem to have learned? These interviews provided rich description of how a negative media attention in the longer run can provide personal and organizational developments from hard pressure and challenging situations.

Furthermore, to widen understanding of the focused subject, we analysed open-ended questions in a web survey for all top managers of public HCSs in Sweden (268 municipal

Published by Sciedu Press
HCS managers and 79 hospital directors). The web survey also included structured items of stress and support which results are presented elsewhere. The following open-ended questions were created to analyse how managers in general perceive, handle and communicate with media: How do you usually communicate and deal with the news media? Describe the most important aspects of and strategies in your communication with the news media; and Describe your experiences of communicating with the news media. The response rate was $60 \%$ among the municipal top managers ( $n=161)$ and only $29 \%$ among the hospital directors $(n=23)$. Therefore, we only included the municipal top managers in the analysis, who represent the majority of the top managers in municipal HCSs in Sweden. Among these, $65 \%$ were female, with a mean experience as manager of 10 years.

The majority of the interviews were transcribed, with the remainder, careful notes were taken. Theoretical memos were written throughout the research process. The raw data, i.e. the transcribed interviews, notes and written answers to open-ended questions, were stepwise coded with open and focused coding parallel with data collection in line with the grounded theory approach. ${ }^{[19]}$ All data was used in the analyses. However, the interview-data had the strongest impact in the building of the model. Data from the open-ended items in the survey confirmed the model. The survey data had a stronger impact on the description of how the work of the media was perceived. This due to the richness in the data of how media was perceived and to provide a more general than local description of how the work of media was perceived in Sweden during the time of the study. The focus of the study was on the managers why no journalists was interviewed. The results should therefore only be considered as management perspectives on the focused issue. The study was approved by the Regional Ethical Review Board in Gothenburg (2008 and 2012).

\section{Results}

\subsection{The story line}

The managers accepted that, in view of the policy of open, transparent governance, dealing with the media is part of the assignment of managers in the public HCS and is crucial for the public's input in care practice in a democratic society. Referring to the different conditions and logics for reporting HCS practices, the managers described challenging imbalances in working with the news media. They employed strategies of putting emphasis on careful correctness and emphasizing decency as well as handling the consequences of biased reporting within their organization and among patients and the public. Thus, their communicating with the media 
in open, transparent management was described as interacting with the media in spite of unequal logics and conditions regarding openness in communicating, and responding to misrepresenting media reporting of the often complex and value-laden issues of HCSs with highlighted dignity, correctness regarding facts and protection of integrity. Managers' approaches further included mobilizing of individual and organizational resources to support openness and decrease uncertainties. They did this both through crafting of individual hardiness and organizational robustness, in the short term, and through a more long-term building of resources with regard to individual and organizational authenticity, a wider awareness of the dynamics involved and finding alternative channels of communication in open management (see Figure 1). In the following, these different categories and their properties will be described, with quotations given.
Figure 1. Managers' perception of their interacting with the media in open, transparent management of HCS

The unequal logics in the manager-media interaction are handled with highlighted dignity and supported by mobilization (crafting and building) of individual and organizational resources.

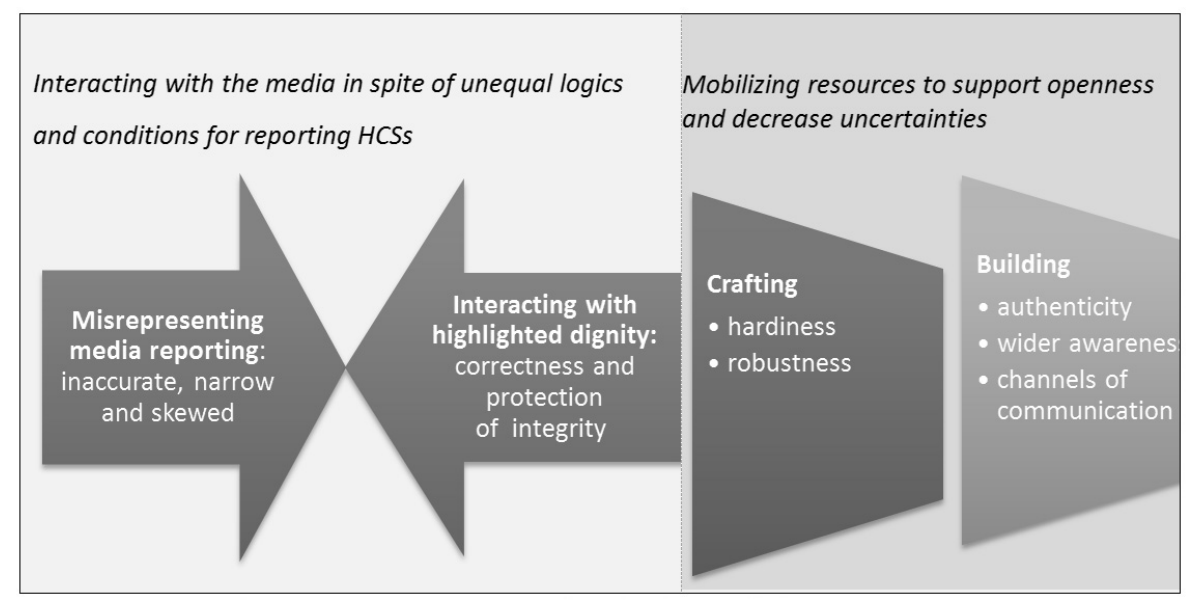

\subsection{Interacting in spite of unequal logics and conditions for reporting}

\subsubsection{Misrepresenting media reporting: inaccurate, nar-} row and skewed

The media experience described by the interviewed managers included all kinds of HCSs, but most commonly elderly and social care as well as emergency and ambulance care. The media reporting focused the public's availability and rights to access HCS, as well as consequences of reorganization of HCSs and changed regulations, in terms of decreased patient safety or the HCS work environment. The reporting often focused a small issue in a broader situation, often through narratives from dissatisfied patients, other members of the public or employees. Dealing with the media was generally not described as a positive or predictable experience as the media reporting was largely experienced as inaccurate and skewed.

"The situation was not described in a truthful manner";

\section{"I found the article misleading."}

This also concerns the tendency of the media to focus on negative aspects and conflicts even when there were no conflicts to report, when the focused matter had been handled correctly, according to decided resource allocations and agreed prioritizing, or to abstain from reporting unless there were negative conflicts to report.

"Journalists almost always present an angle that gives a false picture."

"My experience is that the media do not want balanced reporting ... it does not sell well."

"Reporters [from a government-supported TV news channel] were here and did interviews with staff in a nursing home. They announced after a few weeks that they wouldn't broadcast the story because it showed a positive picture."

"Decisions in the social services tend to be reflected negatively in the media, no matter how correct the decisions are."

The managers also perceived inaccurate reporting due to the narrow perspectives of the media and their focus on the person rather than the system. This means they felt that the media often simplified value-laden conditions and issues in the HCSs and gave a one-sided perspective, and that a single person (often the manager) was often made responsible - rather than the wider system (including political decisions and prioritizing, and the organization's goals and assignments) or the context of caring practice (including the patient, their relatives and the health care professionals).

"In my experience the media has become more focused on finding fault and on blaming one person for being responsible. Whether a matter is well handled or not has little significance."

"It is assumed by the media that we have not done what we 
should; that's their starting point."

Reporting was also perceived to be skewed in situations where the media focused employees' perspectives, when the employees were the source of information. This might be the case, for example, when the internal open management was not effective and occupational groups strongly opposed plans to reorganize, and used the media as a tool.

However, some managers gave a more positive picture of media reporting:

"My experience of the media, during my years as a manager at the job that I have now, has been good. I think they have listened fairly to our views. Past experiences have sometimes been the other way around, when they blew things up and did not stick to the 'truth'."

"Contact with the media is very different depending on whether they are going to write about something that they feel is a catastrophe, or there is a planned interview."

\subsubsection{Interacting with highlighted dignity, correctness re- garding facts, and protection of integrity}

The central quality in managers' approaches to dealing with the media arises from the media's role as setting the rules of the communication, and the perceived risk of inaccurate news media reporting and of being personified. Therefore, the managers were very correct and handled the media with emphasized decency. This means they were very careful about delivering correct facts and taking precautions to be perceived as reliable. It was, for example, important to always be available to the media to reduce insinuating media comments about managers trying to escape from their responsibility to meet with the media. It was also important to be very certain about the focused issue in practice. This implied that they themselves observed the problem in detail in order to embody the knowledge of the focused matter. This increased their certainty in the meeting with the media.

"If you show the slightest uncertainty about the circumstances the media will notice immediately and get you, even if it's not a real problem."

"It is extremely important to give factual, clear and accurate information. To provide them with accurate information will prevent misunderstandings."

"Be prepared when they call or come to visit. Do not think you can give only half of the story."

"I'm very concerned with achieving personal experience of the focused problem in practice - to provide accurate information and strong certainty in the meeting. It is very important to be truthful, action-oriented and accurate even though the media are not truthful."

Published by Sciedu Press
"The answers would have been completely different without my long experience with journalists. My own personal trick is to see them as unusually ignorant 15-year-old and give them information on that level."

Interviewees further said that it was important to communicate reliably within the organization, and with politicians, superiors, subordinates and other persons involved. Managers often chose to let another person observe the meeting with the media to protect their legitimacy within the organization as having met the media with decency. This was a way of protecting the integrity of the organization and all individuals concerned. There was a perceived imbalance between their own delivery of correct and comprehensive facts (while safeguarding the integrity of the persons involved) and the media's choice to report a narrow and simplified story, or even untruths. A feeling of often being prejudged was also described. A special challenge in handling the media was that facts about individual clients and patients as well as employees cannot be reported due to legislation and agreements regarding patient and personnel confidentiality. This could convey the impression of hiding a possible conflict or being uncertain about the matter.

"It is important to protect what is under confidentiality."

"The question of how much information you can give with regard to the confidentiality provisions is important. Crucial but difficult."

\subsection{Mobilizing resources to support openness and de- crease uncertainties}

Inaccurate media reporting, according to the interviewees' descriptions, caused worry within the organization and among patients and other HCS users and their relatives, local society and politicians. The interviewees believed that politicians might easily be influenced by misrepresenting reports in the news media, especially before elections. The skewed reporting of care practices therefore caused deeper concern related to the democratic influence of the media. Consequently, the managers' dealings with the media, conceptualized as mobilizing resources to support openness and decrease uncertainties, had broader goals than a mere handling of challenges related to their own identity and work situation.

"This [certain media reports] created concern and need of clarification. I experienced negative emotions and worry on the part of patients and employees (anxiety, uncertainty, disappointment, irritation, frustration) ..."

"Employees showed frustration over the bad quality of the media reporting."

"It is important to the organization and the people in it to feel 
safe and supported when the media pressure gets tough.”

“The media's influence on decision making feels unsettling. Politicians and decision makers are guided rather easily by the questions that the media focuses on."

“... wish there were also positive stories in the media about the elderly..."

Managers' approaches to decreasing the impact of inaccurate media reporting and supporting open, transperant management were examples of both a short-term crafting and a more long-term building of resources, both as individuals in their managerial role and for the HCS. The success in mobilization of resources was related to the interaction between organizational and individual resources, i.e. the awareness of and preparedness for opportunities and threats of media exposure.

\subsubsection{Crafting managerial hardiness and organizational robustness}

The immediate mobilization of resources included an intensification of communicating with the media and within the organization. This meant efforts were made by managers to increase control and decrease their own uncertainty regarding the focused matter by increasing their knowledge about the focused matter in practice. This involved having practical, experienced, and embodied knowledge about the focused issue. Intensification also meant having a high degree of availability to the media to decrease uncertainties related to how the media would report the focused issue. Crafting hardiness resources also included handling personification in the media. The experience of being violated was related to the degree of personification and in some cases had negative personal consequences.

"The post-traumatic stress you feel from being exposed to hatred focused on you as a person. It is not a day goes by that I don't spontaneously and unconsciously think about what I have experienced. Web comments have led to death threats, etc."

"At a personal level, these hateful comments will haunt me for life as it seems that you cannot eliminate them from the net-facing me in my future career when many might Google me as a relatively senior person ..."

To handle personification meant supporting the focused manager, alternating spokespersons, following a pre-planned media strategy and building a management team who consider communication with the media as a shared responsibility. The crafting of hardiness resources also meant developing an attitude of turning the hard media pressure into opportunities for growth. Managers described how they had mobilized stronger commitment, e.g. through involvement in the fo- cused matter from a wider perspective with a genuine interest, and also through viewing the media situation as a stimulating challenge.

"Being a director of social services to some extent means becoming "thick-skinned". I have in the process become much more critical of everything I read, see and hear."

Organizational robustness meant mobilizing structural and knowledge-based resources. This included developing a documented strategy regarding how contact with the media can be supported, using what organizational resources; building a stable organizational platform facilitating actions; and developing sufficient competence and experience regarding communication with the media in the management team and the communication function and ensuring support in practice from the communication function. Also, relational and emotional resources needed to be mobilized, e.g. the managers had to ensure support from their own boss or colleagues and build a supportive management team.

\subsubsection{Building authenticity and creating awareness and channels of communication}

Mobilizing deeper resources in terms of open, transparent management of health care meant building authenticity and value-based openness and creating an awareness of the conditions. These resources were seen as being the result of reflections and lessons learnt from adversities in interacting with media. The challenging experiences had made many of the managers question their own identity, and their role and core values, which in turn had resulted in them being clearer about and stronger in these aspects, also with regard to the HCS they were in charge of.

"When I met the journalist I clearly put my neck on the block. [I wanted] to illustrate my honest work and show that I was giving him facts that he could trust. His negative attitude turned after a while and we had a good conversation about the problems and circumstances. The article he wrote was a good one."

The authentic approach was central in the complex situation they were facing, with little chance of controlling the process or the outcomes. Building resources included balancing proactive control with acceptance of the process and outcomes. Among individual managers, this was described as a balance between proactive preparedness on the one hand, acting on the conviction that they could influence the situation, and, on the other hand, their active acceptance and awareness when the media process was out of their hand. Within the organization, this meant taking proactive steps in the management team and reporting proactively. For example, the managers frequently wrote press releases that could be 
used verbatim by newspapers. Also, they were continuously building trustable relations with the media, e.g. reporting both good and bad news honestly. The more proactive management teams had a daily agenda for media attention and regularly scheduled media meetings to control the focused matter immediately and delegate the tasks and functions in the media process. They also delegated the responsibility to meet the media in order to decrease personification, and used the organizations' communication functions to improve their communication with the media.

"We [the management team]are taking the media questions on rebound. It is about being the head of the dog and not the tail."

"I act proactively by posting the information on the website."

"We have regular press briefings, with the political chairman of the Board present."

"To build up trust with the local media is important."

"It is important to have a good relationship with the local press and take the opportunity to use the media with the aim to get positive information."

The situation might trigger innovative efforts to build other channels for open, transparent communication around the focused issues, as well as to communicate the more comprehensive picture of the health care practice. Channels of communication included invitations to communicate face to face; the social media; patient associations; placing comments boxes at various locations around the hospital, inviting suggestions and feedback from patients; and conducting open seminars and workshops.

\section{Discussion}

This study contributes to the emerging knowledge about leadership practice in open, transparent management of public HCSs with regard to interacting with the media. The news media are an important channel for communication and are, like the HCSs, interested in increasing democratic processes. However, dealing with the media is challenging because of unequal logics and conditions regarding openness and motives as well as the rules of the game regarding what is reported. Among the managers interviewed in this study, this challenge made them generate approaches to better protect the integrity of their organization, themselves and all concerned. It also made them address widespread uncertainties, regarding HCSs, among patients and their relatives and the public as well as within the organization. However, having to deal with the media also led to improved personal and organizational resource mobilization and growth, and improved ability to handle open management.

Published by Sciedu Press
Still, we interpret the managerial practice of open management as being in an early phase of development. The managers demonstrated increased preparedness to take actions during media attention. Further, the organizations' websites were used to communicate a more comprehensive picture of the service. However, this latter strategy does not present opportunities for two-way communications. The media interaction triggered innovation leading to use of other channels for open communication and a dialogue regarding the HCS.

The media pressure had both negative and positive personal consequences. Negative consequences were related to the degree of personification. Managers who are being personified may experience personal long-term symptoms and consequences in the form of personal indignity. The spread and the degree and consequences of these have been related to uncertainties in the managerial role. ${ }^{[15]}$ The increased interest from the news media in health issues and a media logic that both provides a simplified description of health care and focuses the more complex, value-laden issues of health care, including an assessment of what is right and what is wrong, have contributed to the adversities. Increased demands on the efficiency of health care resources and a lack of internal communication and effective management teams also seem to have increased the focus on the individual manager.

Therefore, handling personification processes as well as supporting sustainable open management requires a wider awareness of roles and dynamics during media attention. This includes awareness of the roles and conditions of managers, journalists and communication functions within an organization as well as of the meaning of open governance and management of public organizations.

The findings of this study show that individual and organizational resources can grow as a result of media pressure. There was growth through the managers' questioning and reflecting upon their own identity and role, and the role of the HCS in a wider context including significant core values and needs of those directly and indirectly involved. Managerial approaches were thus strengthened through the crafting of individual and organizational resources by focusing on the core values and adopting an authentic openness in communicating the service. These findings are in line with another recent, longitudinal study about growth of authenticity in managers as a consequence of adversities during a merger ${ }^{[18]}$ and theories of the development of inner strength. ${ }^{[19]}$ Therefore, the development of managers' identity is influenced by combined organizational and managerial processes, ${ }^{[20]}$ their dealing with contradictory and conflicting logics ${ }^{[21]}$ and the adversities they face. The development of identity through a struggle between personal identity and being a representative 
role model as a manager within the organization has been described in the literature. ${ }^{[10,20,21]}$ This study contributes by describing how mobilization of resources triggered the development of authenticity and wider awareness in the interviewed managers' leadership and in the reporting of their HCS through their dealings with the news media, and through development of practices related to open management.

\subsection{Practical implications}

Communicating with the media today is increasingly common for managers in HCS and an important part of the work is to create trust for the service. ${ }^{[16]}$ The role of authentic leadership to create trust is well documented. ${ }^{[22]}$ This study contributes with knowledge about authentic open management. This can contribute by leading to more value-based and motivated managerial practices and decision making at the operational level. In practice, it is important to develop understanding and knowledge of the dynamics involved and the personification processes. Personified, negative and critical focus in the media can be challenging and associated with negative consequences for the managers. ${ }^{[15]}$ In practice, managers may need both personal and organizational support to handle open, transparent communication with media. They also need to have a close knowledge about the focused issues in practice. Further, knowledge of the practices and conditions for open management among managers can increase certainty in communicating (internal and external) decisions, priorities and working practices. Therefore, it is important to prepare a media strategy of the organization in advance. This must be based on an understanding of and knowledge about the dynamics involved in interactions with the media, and the ambition to enhance open management (It should not be based on defensive action to prevent personification and "witch hunting" of managers.) It is also important to ensure the support of and shared responsibility among the management team. The management team should act proactive and together from a wider awareness of the opportunities and risks in the media communication. In sum, the following actions can be taken to improve conditions for open management:

- Provide personal and organizational support to managers during media communication through superior manager, management team, communication and HRfunction.

- Develop management team to act proactively and together in these issues.

- Develop an open media strategy based on openness and trust - and not defense or personification.

\subsection{Methodological limitations and strengths}

This study has focused only on managers' perspectives. The study's methodological strengths are the longitudinal design, with strategic and representative sampling procedures. A strength is the wide and comprehensive data-collection with: (1) interviews with managers with clearly negative experiences in the shorter- and longer-term, (2) interviews with managers with general experiences, (3) open-ended questions from a survey to all public HCS-managers in Sweden. Further, the study was conducted over a time-period when the media landscape changed from news media to a dominance of social media. The work situation of the journalists also changed, with increased time-pressures, during this period but seemed to vary locally. Despite this, our model describes managers' central experiences and the model can be understood and transferred with knowledge of local, contextual variations. A wider understanding of the interaction between the media and managers would also need to include the perspectives of the media. However, we have invited journalists and media actors to comment on our findings, which has confirmed the situation regarding personification and lack of perspectives in reporting. The journalists and media actors have also provided explanations for the logics for reporting. ${ }^{[16]}$

\section{Conclusions}

Media contact can have vital importance for open management of HCS but managers and the media differ with regard to logics for reporting. Awareness of opportunities and threats of media communication and mobilization of resources may be crucial for open management and for more accurate reporting of the HCS.

Today, open management and interaction with the media is common for managers in health care. Media contact has also become an important part of the manager's psychosocial work environment and sustainability, as a person-focused, negative and critical focus in the media can be challenging and can have broader implications for both the manager and the public image of the HCS. There are limited opportunities for control over exposure and development of a media story. Therefore, it is important to develop a wider awareness of the processes that are related to the media contact. Awareness of opportunities and possible consequences of media contact and the mobilization of the individual and organizational resources can be crucial in supporting open management and achieving a more accurate picture of HCSs in the media. To support open management of public HCSs, media strategy ought to be based on the intention to increase openness, insight and participation. The focus should not be on avoidance of personification and "witch hunting", by the 
media, of individual managers.

\section{ACKNOWLEDGements}

We are grateful for financial support from AFA Insurance (an organisation owned by Sweden's labour market parties) and University of Borås.

\section{CONFLicts OF INTEREST Disclosure}

There are no competing interest to declare, either financial or non-financial.

\section{REFERENCES}

[1] Feller J, Finnegan P, Nilsson O. Open Innovation and Public Administration: Transformational Typologies and Business Model Impacts. Europ J Inform System. 2011; 20: 358-374. https ://doi . org/10 $.1057 /$ ejis. 2010.65

[2] Lathrop D, Ruma L. Open Government. Collaboration, Transparency, and Participation in Practice. Sebastopol, CA, US: O'Reilly Media Inc; 2010.

[3] Lathrop D, Ruma L. Open Government. Collaboration, Transparency, and Participation in Practice. Sebastopol, CA, US: O'Reilly Media Inc; 2010. PMid: 23453568. https://doi.org/10.1016/j.ej on. 2013.01 .005

[4] Clar C, Dyakova M, Curtis K, et al. Just telling and selling: current limitations in the use of digital media in public health: A scoping review. Public Health. 2014; 128: 1066-1075. PMid: 25443388. https://doi.org/10.1016/j.puhe. 2014.09.009

[5] Weibull L, Oscarsson H, Bergström A. Svenska trender 1986-2011 (Swedish trends) [In Swedish]. Gothenburg: SOM Insitute, University of Gothenburg; 2012.

[6] Engwall M. Minerva and the media: Universities protecting and promoting themselves. In European Universities in Transition Edited by Mazza C, Quattrone P, Riccaboni A, London, UK: Edward Elgar; 2008. https://doi.org/10.4337/9781848441415.00012

[7] Yukl G. Leadership in organizations. Englewood Cliffs, N.J: Prentice Hall; 1998.

[8] Power M. Organized Uncertainty. Designing a world of risk management. Oxford, UK: Oxford University Press; 2007.

[9] Arman R, Wikström E, Dellve L. Managerial communication practices. Health care managers' everyday structuration. Scand J Public Admin. 2012; 16: 143-163.

[10] Alvesson M. The Triumph of Emptiness. Consumption, Higher Education, and Work Organization. Oxford, England: Oxford University Press; 2013.

[11] Kjaer P. The organizing media: how mass media influence organisations. I: Exploring the Worlds of Mercury and Minerva. Wedlin L, Sahlin K, Grafström M (red). Uppsala: Acta Universitatis Upsaliensis; 2009.
[12] Grafström M, Karlberg PP, Windell K. Föredöme eller Fördömd. Medierna som moralisk domstol [Role model or damned. The media as a moral court]. Stockholm, Stockholm: SNS förlag; 2013.

[13] Pollit C, Bouckaert G. Public Management Reform: A Comparative Analysis. Oxford: Oxford University Press; 2000.

[14] Schillemans T. Mediatization of public services: How organizations adapt to news media. Frankfurt am Main: Peter Lang; 2012. PMid: 23350206.

[15] Wilmar MW, Ahlborg G, Jacobsson C, et al. Healthcare managers in negative media focus: a qualitative study of personification processes and their personal consequences. BMC Health Services Research. 2014; 14: 8. PMid: 24397306. https://doi.org/10.1186/1472 $-6963-14-8$

[16] Dellve L, Wilmar MW, Jacobsson C, et al. Ledarskap i vården: Att möta media och undvika personfokuserade drev [Leadership in health care service: meeting media and avoiding personified followings]. Högskolan Borås: Vetenskap för profession 28; 2014.

[17] Charmaz K. Constructing Grounded Theory - a Practical Guide through Qualitative Analysis. London: SAGE Publishing Inc; 2006.

[18] Kira M, Balkin DB, San E. Authentic Work and Organizational Change: Longitudinal Evidence from a Merger. J Change Managem. 2012; 12: 31-51. https://doi.org/10.1080/14697017.2011. 652374

[19] Lundman B, Aléx L, Jonsén E, et al. Inner strength-A theoretical analysis of salutogenic concepts. Int J Nurs Stud. 2009; 47: 251260. PMid: 19577237. https://doi.org/10.1016/j.ijnurs tu.2009.05.020

[20] Andersson T. Identity Work and Identity Regulation in Managers' Personal Development Training. Gothenburg Sweden: GRI University of Gothenburg; 2008.

[21] Alvesson M. Self-doubters, strugglers, storytellers, surfers and others: Images of self-identities in organization studies. Human Relations. 2010; 63: 193-217. https://doi.org/10.1177/001872670935 0372

[22] Avolio BJ, Walumbwa FO, Weber TJ. Leadership: Current theories, research and future directions. Ann Rev Psychol. 2009; 60: 421-449. PMid: 18651820. https://doi.org/10.1146/annurev.psych. 60.110707 .163621 